\title{
Estabilidade da produção e da capacidade de combinação de diferentes populações de aveia
}

\section{Yield and combining ability stability in different oat populations}

\author{
Igor Pirez Valério ${ }^{1}$; Fernando Irajá Félix de Carvalho ${ }^{2}$; Antonio Costa de Oliveira ${ }^{2 *}$; \\ Claudir Lorencetti ${ }^{3}$; Velci Queiroz de Souza ${ }^{4}$; José Antonio Gonzáles da Silva ${ }^{5}$; \\ Irineu Harwig'; Douglas André Mallmann Schmidt; \\ Ivandro Bertan ${ }^{6}$; Guilherme Ribeiro ${ }^{8}$
}

\begin{abstract}
Resumo
O uso da estabilidade em associação à análise dialélica pode representar uma forte ferramenta para a previsibilidade de seleção de caracteres quantitativos. Desta forma, o presente trabalho teve por objetivo testar a estabilidade de diferentes populações de aveia, oriundas de combinações envolvendo cinco genitores (UPF 16, UPF 18, UFRGS 7, UFRGS 17 e URPel 15), com base nas estimativas da capacidade geral e específica de combinação destes genótipos. O delineamento adotado foi o de blocos casualizados com três repetições. Os experimentos foram conduzidos no Centro Agropecuário da Palma, na área experimental do Centro de Genômica e Fitomelhoramento, localizado no município de Capão do Leão/ RS, nos anos de 2002 (um experimento) e 2003 (dois experimentos), formando três ambientes. Para a discriminação das melhores constituições genéticas com base na estabilidade do efeito de capacidade específica de combinação, foi determinante o uso de avaliações em diferentes gerações e anos de cultivo. Os cruzamentos entre UPF 16 x UPF 18, UPF 16 x UFRGS 7 e UPF 16 x UFRGS 17, se revelam promissores no incremento do rendimento de grãos via seleção indireta através do número de panículas por planta, número de grãos por panícula e peso de panícula, respectivamente.

Palavras-chave: Avena sativa L, análise dialélica, previsibilidade e melhoramento genético de plantas.
\end{abstract}

\begin{abstract}
The association of stability indexes and diallel analyses can provide a strong tool for the predictability of selecting quantitative traits. Therefore, the present work had as objective to test the stability of different oat populations, originating from the combination of five parental genotypes (UPF 16, UPF 18, UFRGS 7, UFRGS 17 and URPel 15) as assessed by their general and specific combining abilities. The experimental design consisted of random blocks with three replications. The experiments were performed in the Centro Agropecuário da Palma, in the experimental field belonging to the Centro de Genômica e Fitomelhoramento, in Capão do Leão county, Rio Grande do Sul state. The essays were
\end{abstract}

1 Eng. Agr., M.Sc., Doutorando em Agronomia (CAPES). Centro de Genômica e Fitomelhoramento (CGF) - Faculdade de Agronomia “Eliseu Maciel” (FAEM)/Universidade Federal de Pelotas (UFPel). Pelotas, RS. E-mail: igorvalerio@gmail.com

2 Eng. Agr., M.Sc., PhD. em Genética e Melhoramento de Plantas - Docente no CGF/FAEM/UFPel. Pelotas, RS.

3 ALLIANCE ONE. Departamento de Pesquisa e Melhoramento de Plantas, C.P. 96880-000 - Vera Cruz, RS.

4 Eng. Agr., M.Sc., D.Sc. em Agronomia, Pós-Doutorando Júnior (CNPq). CGF/FAEM/UFPel. Pelotas, RS.

5 Eng. Agr., M.Sc., D.Sc em Agronomia - Docente do Departamento de Estudos Agrários da Universidade Regional do Noroeste do Estado do Rio Grande do Sul (UNIJUÍ). Ijuí, RS.

6 Syngenta Seeds Ltda. - Unidade de Pesquisa \& Desenvolvimento - Santa Tereza D'Oeste, PR.

7 Eng. Agr., M.Sc., Doutorando em Agronomia (CAPES). CGF/FAEM/UFPel. Pelotas, RS.

8 Eng. Agr., Mestrando em Agronomia (CAPES). CGF/FAEM/UFPel. Pelotas, RS.

Autor para correspondência.

Recebido para publicação 08/02/08 Aprovado em 04/12/08 
performed in 2002 and 2003, as one and two experiments, respectively, adding up to three environments. The evaluation in different generations and years was essential to discriminate well the genotypes for the stability of their specific combining ability effects. The crosses UPF $16 \times$ UPF 18, UPF $16 \times$ UFRGS 7 and UPF $16 \times$ UFRGS 17 were found to be promising regarding the increase grain yield by indirect selecting number of panicles per plant, number of grains per panicle and panicle weight, respectively.

Key words: Avena sativa $\mathrm{L}$, diallel analysis, grain yield and plant breeding

\section{Introdução}

A aveia branca (Avena sativa L.) constitui uma fonte com potencial econômico de produção de grãos e qualidade nutricional para alimentação humana e animal, sendo considerada de grande importância como cultura de estação fria no Sul do Brasil (BARBOSA NETO et al., 2000). Desta forma, torna-se constante a necessidade para os melhoristas de aveia, disponibilizar permanentemente genótipos superiores com alta produtividade e que demonstrem estabilidade de produção. Para atingir estes objetivos, os programas de melhoramento de aveia precisam ser dinâmicos, rápidos e eficientes, de modo a atender as expectativas dos agricultores e do mercado consumidor.

O comportamento dos genótipos envolvidos em cruzamentos artificiais, seus híbridos $\mathrm{F}_{1}$ e gerações subseqüentes, é digno de investigações, por predizer as potencialidades e fornecer estimativas de parâmetros genéticos essenciais no direcionamento de hibridações e seleção de constituições genéticas superiores em programas de melhoramento. Dentro deste contexto, a análise de cruzamentos dialélicos é de grande utilidade (LEFFEL; WEISS, 1958). Os sistemas de cruzamentos dialélicos são bastante utilizados no melhoramento de plantas, uma vez que possibilitam a avaliação da capacidade combinatória e do potencial heterótico de variedades ou linhagens em cruzamentos, ou nos estudos básicos da estrutura genética das populações (GERALDI; MIRANDA FILHO, 1988).

Diversos tipos de análise dialélica podem ser utilizadas: balanceados, parciais, circulantes, incompletos e desbalanceados (CRUZ; REGAZZI; CARNEIRO, 2004). Destes, merece destaque o dialelo balanceado de Griffing (1956), que considera a análise dialélica conjunta. Neste procedimento, é avaliado o efeito da interação entre os componentes da capacidade combinatória e o ambiente, pelas estimativas dos parâmetros das análises dialélicas descrito por Griffing (1956), e de estabilidade e adaptabilidade conforme proposto por Eberhart e Russell (1966).

A avaliação de genótipos superiores que considera a análise individual de ambientes (anos específicos) conduz normalmente a escolhas deficitárias, devido aos fortes efeitos da interação genótipo x ambiente, impossibilitando uma melhor identificação de constituições genéticas superiores com base no comportamento médio em diferentes ambientes. Esta dificuldade, relatada por Allard (1999), vem destacando os anos de cultivo como o efeito de ambiente que proporciona ao melhorista a maior dificuldade de avaliação, principalmente em populações segregantes onde se espera obter ganhos com a seleção. Diversos autores, avaliando locais e anos, concluíram que o fator ano foi o de maior importância para a instabilidade de produção da cultura da aveia, sendo o local de pequena contribuição (BENIN et al., 2005a; CARVALHO et al., 1982; FEDERIZZI et al., 1993; LORENCETTI et al., 2004).

A dificuldade em prever o desempenho das melhores constituições genéticas, em ambientes individualizados, destaca a relevância do uso de modelos de dialelo em associação ao índice de estabilidade. Isso representa uma forte ferramenta no que diz respeito à maior previsibilidade de seleção de caracteres desejáveis. Dentro deste contexto, Pacheco, Cruz e Santos (1999), destacam o uso desta associação, como uma nova metodologia que permite inferências na adaptabilidade e 
estabilidade da capacidade geral e específica de combinação, provendo numa excelente alternativa para apresentar os resultados de análises dialélicas conduzidas em uma série de ambientes. Deste modo, os melhores genótipos serão aqueles com maiores efeitos de capacidade geral de combinação (CGC) ou capacidade específica de combinação (CEC) associado ao comportamento previsível frente às gerações ou anos de cultivo.

Dada a importância da realização de estudos nesta área, o objetivo do trabalho foi testar a estabilidade de diferentes populações de aveia com base nas estimativas da capacidade geral e específica de combinação, e predizer os cruzamentos promissores que possibilitem ganho genético em caracteres relacionados à produção de grãos.

\section{Material e Métodos}

O experimento foi instalado em campo experimental pertencente ao Centro de Genômica e Fitomelhoramento (CGF) da Faculdade de Agronomia Eliseu Maciel UFPel, no município de Capão do Leão-RS, no ano agrícola de 2002 e 2003. Foram utilizados cinco genótipos de aveia branca (UPF 16, UPF 18, UFRGS 7, UFRGS 17 e URPel 15) submetidos a cruzamentos artificiais conforme modelo dialélico completo sem os recíprocos resultando em dez combinações híbridas. As sementes $F_{1}$ de cada combinação foram obtidas em casa-de-vegetação no período de estação quente no ano de 2002, sendo uma amostra armazenada a fim de ser semeada na estação fria de 2003. Neste mesmo ano, no período recomendado de cultivo, foi desenvolvido experimento com a população $\mathrm{F}_{1}$ e seus respectivos genitores. No ano de 2003 foram instaladas a campo dois experimentos, com as gerações $F_{1}$ (armazenadas do ano anterior), e com a geração $\mathrm{F}_{2}$ e genitores, de modo a compor o estudo envolvendo gerações em distintos anos de avaliação, sendo considerados, portanto como três experimentos.
A semeadura realizada nos três experimentos foi feita de modo manual, sendo que para aquelas que não germinaram ou ainda que não produziram sementes, foram consideradas na análise como parcela perdida. As plantas foram conduzidas em linhas de $3 \mathrm{~m}$ de comprimento, com espaçamento de $0,3 \mathrm{~m}$ entre plantas e entre linhas. $\mathrm{O}$ delineamento adotado nos dois anos de avaliação foi o de blocos casualizados com três repetições, sendo a planta individual considerada uma unidade de observação. Foi utilizado como efeito de bordadura do experimento uma linha cheia de trigo, ao redor de cada experimento.

Foram avaliados os seguintes caracteres nos dois anos de cultivo: número de grãos por panícula (NG $\left.\mathrm{P}^{-1}\right)$, contado na panícula principal de cada da planta; número de panículas por planta $\left(\mathrm{NP}^{-1}\right)$, por meio da contagem do número de afilhos férteis de cada planta individualmente; produção de grãos por planta (PG $\left.\mathrm{P}^{-1}\right)$ por meio de trilha individual de cada planta (em gramas); e peso de panícula (PP), obtido mediante o peso da panícula principal (em gramas).

Anteriormente à realização da análise de variância, os dados foram testados quanto às pressuposições estatísticas, sendo que todas as variáveis foram ajustadas utilizando a equação $\log _{10}(\mathrm{x})$. Posteriormente, os dados foram submetidos à análise de variância utilizando o programa computacional SAS Learning Edition (2002). Após foi realizada a análise conjunta de Griffing (1956), que associa análise dialélica com a de adaptabilidade e estabilidade, onde as somas de quadrados dos tratamentos foram decompostas em CGC e CEC e interações por meio da análise de variância dialélica, com auxílio do Programa Genes (CRUZ, 2001).

Para discussão dos dados, não foi levado em consideração o índice de adaptabilidade, em virtude de que o objetivo principal do trabalho foi verificar a previsibilidade dos coeficientes de CGC e CEC para as constituições genéticas avaliadas nos diferentes ambientes $\left(\mathrm{E}_{1}=\mathrm{F}_{1}-2002, \mathrm{E}_{2}=\mathrm{F}_{1}-2003\right.$ e $\mathrm{E}_{3}=\mathrm{F}_{2}$ $-2003)$. 
No procedimento de análise dialélica conjunta, para avaliação dos efeitos da interação entre os componentes da capacidade combinatória e o ambiente, foram adotados os seguintes modelos, conforme Pacheco, Cruz e Santos (1999):

1) Para análise dialélica em cada ambiente

$$
Y_{i j}=\mu+G_{i}+G_{j}+S_{j}+\bar{\varepsilon}_{j} \text {, onde: }
$$

$\mu$ : efeito da média geral; $G_{i}$ e $G_{j}$ : efeitos da capacidade geral de combinação (C.G.C.) associados ao $i$ e j-ésimo genitor; $S_{i j}$ : efeito da capacidade específica de combinação (C.E.C) entre os progenitores $i$ e $j ; Y_{i j}$ e $\bar{\varepsilon}_{i j}$ são, respectivamente, a média experimental e o erro aleatório médio associado ao tratamento de ordem $i j$.

2) Para análise dialélica conjunta

$Y_{i j}=\mu+G_{i}+G_{j}+S_{i j}+A_{k}+G A_{i k}+G A_{j k}+S A_{i j k}+\bar{\varepsilon}_{i j}$, onde:

$A_{k}$ : efeito do ambiente $k ; G A_{i k}$ e $G A_{j k}$ : efeitos da interação entre a capacidade geral de combinação (C.G.C.) associados ao $i$ e j-ésimo genitor com os ambientes, respectivamente; $S A_{i j k}$ : efeito da interação entre a capacidade específica de combinação (C.E.C) entre os genitores $i$ e $j$ e o ambiente.

3) Para associação entre análise dialélica e análise de estabilidade e adaptabilidade.

$Y_{i j k}=\beta_{0}+\beta_{1} l_{k}+\hat{\sigma}_{d(C G C) o u(C E C)}^{2}+\bar{\varepsilon}_{i j k}$, onde:

$Y_{i j k}$ : média do tratamento $i j$ (genitor $i$, quando $i=j$, ou híbrido $i j$, quando $i \# j$ ) no ambiente $k$; $\beta_{0}$ : média do tratamento $i j ; \beta_{1}$ : coeficiente da regressão que expressa a adaptabilidade do tratamento $i j ; l_{k}$ : índice de ambiente; $\bar{\varepsilon}_{i j k}:$ erro experimental médio.

$\wedge^{2}$

$\sigma_{d(C G C) o u(C E C)}$ : desvio da regressão, seguindo os seguintes modelos abaixo, conforme adaptação de Cruz, Regazzi e Carneiro (2004).

$Q \operatorname{MDES}(\operatorname{cgc})_{\text {ou }}(\mathrm{cec})=\frac{\operatorname{SQDES}(\mathrm{cgc})_{\text {ou }}(\mathrm{cec})}{a-2}$,

onde:

QMDES $(\mathrm{cgc})_{\text {ou }}(\mathrm{cec})=$ quadrado médio dos desvios da regressão para os efeitos da capacidade geral e específica; $S Q D E S(\operatorname{cgc})$ ou $(c e c)=$ soma de quadrados dos desvios da regressão para os efeitos da capacidade geral ou específica; $a=$ número de ambientes considerados.

$$
\hat{\sigma}_{d(C G C)_{o u}(C E C)}^{2}=\frac{Q M D E S(\operatorname{cgc}) \text { ou }(\mathrm{cec})-Q M R}{r},
$$

onde:

$$
\begin{aligned}
& \hat{\sigma}_{d(C G C) o u(C E C)}^{2}=\text { desvios da regressão da constituição } \\
& \text { genética } i \text {, considerando os efeitos da CGC ou CEC } \\
& \text { nos ambientes de teste, } Q M R=\text { quadrado médio do } \\
& \text { resíduo da análise dialélica conjunta, } r=\text { número de } \\
& \text { repetições. }
\end{aligned}
$$

${ }_{\wedge_{2}}$ Sendo testado a significância do parâmetro $\hat{\sigma}_{d(C G C) o u(C E C)}$ para cada constituição genética pelo seguinte teste F:

$$
F=\frac{Q M D E S(\mathrm{cgc}) \text { ou }(\mathrm{cec})}{Q M R}
$$

Quando o desvio da regressão foi estatisticamente diferente de zero, ou seja, de baixa previsibilidade, foi utilizado a medida auxiliar representada pelo coeficiente de determinação $\left(R_{i}^{2}\right)$,

$$
R_{i}^{2}: \frac{S Q(\text { reg.linear }) i}{S Q(A / G i)} \times 100, \text { onde: }
$$

$R_{i}^{2}=$ coeficiente de determinação; $S Q$ (reg.linear $) i$ = soma de quadrado da regressão linear do genótipo; 
$S Q(A / G i)=$ soma de quadrado de ambiente dentro de genótipo.

Os dados também foram submetidos à análise de médias comparando os três ambientes em cada tratamento pelo teste de Tukey a 5\% de probabilidade de erro, e para comparação dos tratamentos dentro de cada ambiente foi utilizado o teste de Scott Knott com o mesmo nível de significância. Foi empregada a análise de correlação de Spearman para identificar a possível associação entre os ambientes avaliados, considerando para isso os efeitos de CGC e CEC em cada tratamento.

\section{Resultados}

Conforme evidenciam os dados na Tabela 1, para a análise de variância conjunta, considerando o fator tratamento (cinco genitores e dez combinações) e ambiente (E), foi detectada interação em todos os caracteres. Entretanto, os caracteres $\mathrm{PG} \mathrm{P}^{-1}$ e NP $\mathrm{P}^{-1}$ não sofreram influência da geração ou ano de avaliação quanto a CGC. Com relação à análise individual dos efeitos simples (para o $\mathrm{E}_{2}=\mathrm{F}_{1}-2003 \mathrm{e}$ $\mathrm{E}_{3}=\mathrm{F}_{2}-2003$ ) podem ser observadas diferenças em todos os tratamentos e efeitos combinatórios (CGC e CEC) com base na expressão dos caracteres nas gerações avaliadas. Já em relação ao $\mathrm{E}_{1}$ (geração $\mathrm{F}_{1}$ conduzida no ano de 2002), não foi constatado o mesmo comportamento, visto que a $\mathrm{CEC}$ não diferiu para o caráter NP $\mathrm{P}^{-1}$.

Tabela 1. Análise de variância pelo modelo de análise dialélica conjunta, para quatro caracteres ${ }^{(1)}$ de aveia. CGF/ FAEM UFPel, Pelotas, 2003.

\begin{tabular}{|c|c|c|c|c|c|}
\hline \multicolumn{6}{|c|}{ Quadrados médios (QM) - Análise conjunta } \\
\hline Fontes de Variação & GL & $\mathrm{PG} \mathrm{P}^{-1}$ & $\mathrm{NP} \mathrm{P}^{-1}$ & $\mathrm{NG} \mathrm{P}^{-1}$ & PP \\
\hline Tratamento & 14 & $0,314 *$ & $0,326^{*}$ & $0,288^{*}$ & $0,341^{*}$ \\
\hline CGC & 4 & $0,353 *$ & $0,980 *$ & $0,554 *$ & $0,442 *$ \\
\hline CEC & 10 & $0,298 *$ & 0,064 & $0,182 *$ & $0,301 *$ \\
\hline Ambiente & 2 & & & & \\
\hline Tratamento x Ambiente (E) & 28 & $0,093 *$ & $0,040^{*}$ & $0,044^{*}$ & $0,036^{*}$ \\
\hline CGC x E & 8 & 0,051 & 0,032 & $0,051^{*}$ & $0,024 *$ \\
\hline CEC x E & 20 & $0,110^{*}$ & $0,044 *$ & $0,041^{*}$ & $0,040^{*}$ \\
\hline Resíduo & 84 & 0,038 & 0,017 & 0,010 & 0,011 \\
\hline Coeficiente de Variação $(\%)$ & & 14,02 & 10,08 & 3,93 & 13,35 \\
\hline \multicolumn{6}{|c|}{$\mathrm{QM}-$ Análise Individual $\mathrm{E}_{1}\left(\mathrm{~F}_{1}-2002\right)$} \\
\hline Tratamento & 14 & 0,135 & $0,088^{*}$ & $0,139^{*}$ & $0,095^{*}$ \\
\hline CGC & 4 & 0,019 & $0,198 *$ & $0,335^{*}$ & $0,150 *$ \\
\hline CEC & 10 & $0,182 *$ & 0,044 & $0,060^{*}$ & $0,074 *$ \\
\hline Resíduo & 28 & 0,066 & 0,032 & 0,016 & 0,021 \\
\hline Coeficiente de Variação $(\%)$ & & 7,90 & 8,24 & 2,52 & 8,13 \\
\hline \multicolumn{6}{|c|}{$\mathrm{QM}$ - Análise Individual $\mathrm{E}_{2}\left(\mathrm{~F}_{1}-2003\right)$} \\
\hline Tratamento & 14 & $0,267^{*}$ & $0,175^{*}$ & $0,150^{*}$ & $0,205^{*}$ \\
\hline CGC & 4 & $0,249 *$ & $0,473 *$ & $0,212^{*}$ & $0,207 *$ \\
\hline CEC & 10 & $0,275^{*}$ & $0,057 *$ & $0,125^{*}$ & $0,204^{*}$ \\
\hline Resíduo & 28 & 0,029 & 0,010 & 0,010 & 0,006 \\
\hline Coeficiente de Variação (\%) & & 6,20 & 5,34 & 2,17 & 5,11 \\
\hline \multicolumn{6}{|c|}{$\mathrm{QM}$ - Análise Individual $\mathrm{E}_{3}\left(\mathrm{~F}_{2}-2003\right)$} \\
\hline Tratamento & 14 & $0,098^{*}$ & $0,142 *$ & $0,087^{*}$ & $0,113^{*}$ \\
\hline CGC & 4 & $0,188^{*}$ & $0,372 *$ & $0,108 *$ & $0,132 *$ \\
\hline CEC & 10 & $0,062 *$ & $0,051^{*}$ & $0,078 *$ & $0,105^{*}$ \\
\hline Resíduo & 28 & 0,020 & 0,009 & 0,005 & 0,006 \\
\hline Coeficiente de Variação (\%) & & 5,42 & 5,06 & 1,52 & 5,52 \\
\hline
\end{tabular}

(1) Caracteres: PG P ${ }^{-1}$ (produção de grãos por planta), NP $\mathrm{P}^{-1}$ (número de panículas por planta), NG $\mathrm{P}^{-1}$ (número de grãos por panícula) e PP (peso de panícula). * Significativo ao nível de $5 \%$ de probabilidade de erro pelo teste $\mathrm{F}$. 
Através dos valores do quadrado médio (QM) para a CEC na geração $\mathrm{F}_{1}-2003\left(\mathrm{E}_{2}\right)$ e $\mathrm{F}_{2}-2003\left(\mathrm{E}_{3}\right)$, para $\mathrm{PG} \mathrm{P}^{-1}$ verifica-se forte redução do vigor de $\mathrm{F}_{1}$ a $\mathrm{F}_{2}$, com 0,275 para 0,062 de QM, respectivamente. Já com base nas análises individuais de cada ambiente, os valores dos QM da CGC foram superiores aos da CEC para todos os caracteres avaliados, exceto para PG P-1 no $E_{1}\left(F_{1}-2002\right)$ e $E_{2}\left(F_{1}-2003\right)$ (Tabela 1).

Conforme verificado na Tabela 2, para análise de médias do caráter PG $\mathrm{P}^{-1}$, o genótipo UPF 16, foi o único a evidenciar desempenho superior, diferindo significativamente dos demais genitores na média conjunta dos três ambientes. Com relação às combinações híbridas, cinco cruzamentos destacaram-se: CR1(UPF 16 / UPF 18), CR2 (UPF 16 / UFRGS 7), CR3 (UPF 16 / UFRGS 17), CR9 (UFRGS 7 / URPEL 15) e CR10 (UFRGS 17 / URPEL 15), com média superior. Já em relação ao caráter $\mathrm{NP} \mathrm{P}^{-1}$, o genótipo UPF 16, confere ao lado do genótipo UFRGS 7, desempenho superior, não diferindo significativamente entre si, sendo a combinação dos dois genitores (CR2), o cruzamento de maior desempenho para o caráter.

Dentre os genótipos avaliados, UPF 18 evidenciou um comportamento muito superior aos

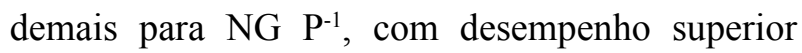
em todos os ambientes de teste, o mesmo pode ser verificado para o caráter PP. As combinações híbridas CR1, CR2, CR5 (UPF 18 / UFRGS 7) e CR9, obtiveram desempenho médio superior aos demais, contudo de grande destaque para o CR1, em virtude de ser o único cruzamento a não evidenciar diferença significativa entre os ambientes de teste, para o caráter. Em relação ao caráter PP, o CR1 foi novamente o de maior destaque, com desempenho estatisticamente superior às outras combinações, e aos próprios genitores envolvidos no dialelo.

De acordo com os dados da Tabela 3, em relação ao índice de estabilidade $\left(\hat{\sigma}_{d}^{2}\right)$ pode ser verificado que não houve diferença significativa entre os genitores com relação aos efeitos de CGC para os quatro caracteres avaliados. Com base nos efeitos da CGC, para o caráter $\mathrm{PG}^{\mathrm{P}} \mathrm{p}^{1}$ podem ser indicados os genótipos UPF 16 e UFRGS 7 como os únicos a apresentar valores positivos na média conjunta dos ambientes testados, apresentando, ainda, o mesmo comportamento para o caráter $\mathrm{NP}^{-1}$. Com

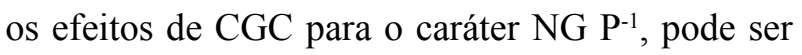
observado o bom desempenho dos genótipos UPF 18 e UFRGS 7, com efeito positivo em todos os ambientes. Entretanto, o primeiro revela os maiores valores de CGC. O mesmo desempenho pode ser verificado no caráter PP para UPF 18, onde é o único genótipo com valores positivos de CGC em todos os ambientes de teste.

Conforme os parâmetros de $\operatorname{CEC~}\left(\mathrm{s}_{\mathrm{ii}}\right.$ e $\left.\mathrm{s}_{\mathrm{ij}}\right)$, há predominância de valores de $\mathrm{s}_{\mathrm{ii}}$ (comportamento per se) negativos para os caracteres $\mathrm{PG} \mathrm{P}^{-1}$, NG $\mathrm{P}^{-1} \mathrm{e}$ $\mathrm{PP}$ e positivos para o caráter $\mathrm{NP}^{-1}$, com todos os genótipos de boa previsibilidade $\left(\sigma_{d}=0=0\right)$, exceto para UPF 18 nos caracteres NG P ${ }^{-1}$ e PP (Tabela 4). Sendo que UPF 16 e UPF 18, apresentam valores negativos de magnitude mais elevada para $\mathrm{PG} \mathrm{P}^{-1}$, o mesmo fato pode ser evidenciado nos caracteres $\mathrm{NG}$ $\mathrm{P}^{-1}$ e PP, para o genótipo UPF 16. 


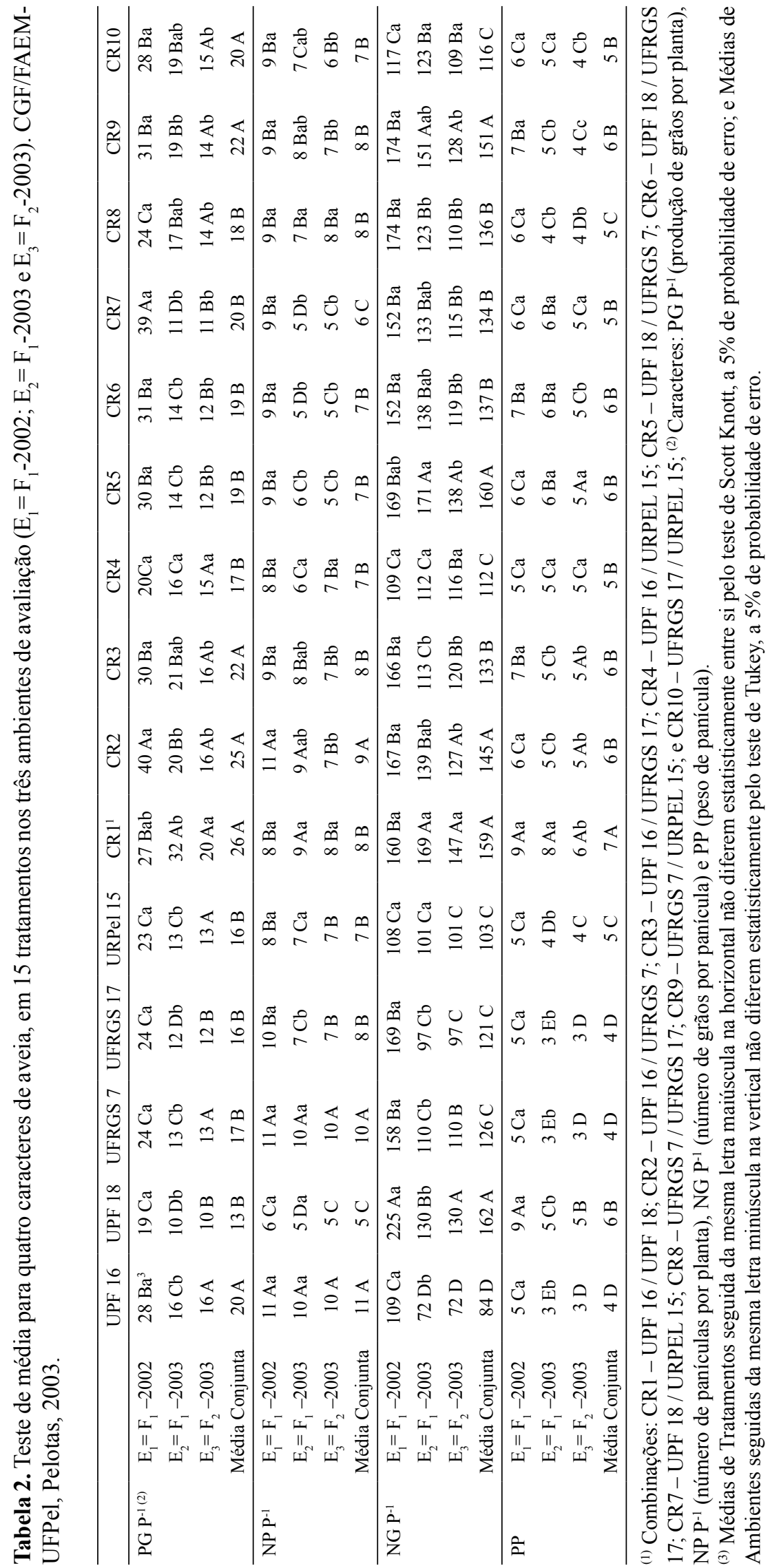


Tabela 3. Capacidade geral de combinação $\left(g_{\mathrm{i}}\right)$ e índice de estabilidade $\left(\hat{\sigma}_{d(C G C)}^{2}\right)$ de cinco genitores de aveia, em quatro caracteres, para os três ambientes avaliados. CGF/FAEM-UFPel, Pelotas, 2003.

\begin{tabular}{|c|c|c|c|c|c|c|}
\hline \multirow{2}{*}{ Caracteres $^{1}$} & \multirow{2}{*}{ Geração e Anos avaliados } & \multicolumn{5}{|c|}{ Genótipos } \\
\hline & & UPF 16 & UPF 18 & UFRGS 7 & UFRGS 17 & URPel 15 \\
\hline \multirow[t]{6}{*}{$\mathrm{PG} \mathrm{P}^{-1}$} & $\mathrm{E}_{1}=\mathrm{F}_{1}-2002$ & 0,027 & $-0,022$ & 0,038 & $-0,028$ & $-0,016$ \\
\hline & $E_{2}=F_{1}-2003$ & 0,176 & $-0,12$ & 0,007 & $-0,023$ & $-0,04$ \\
\hline & $\mathrm{E}_{3}=\mathrm{F}_{2}-2003$ & 0,149 & $-0,11$ & 0,006 & $-0,036$ & $-0,01$ \\
\hline & Média Conjunta & 0,118 & $-0,084$ & 0,017 & $-0,029$ & $-0,022$ \\
\hline & $\hat{\sigma}_{d(C G C)}^{2}$ & $-11,2^{\mathrm{ns}}$ & $-12,4^{\text {ns }}$ & $-12,8^{\mathrm{ns}}$ & $-12,8^{\mathrm{ns}}$ & $-12,4^{\mathrm{ns}}$ \\
\hline & $\mathrm{R}^{2}$ & 86,50 & 91,00 & 99,00 & 5,00 & 6,00 \\
\hline \multirow[t]{6}{*}{$\mathrm{NP} \mathrm{P}^{-1}$} & $\mathrm{E}_{1}=\mathrm{F}_{1}-2002$ & 0,056 & $-0,144$ & 0,111 & 0,014 & $-0,037$ \\
\hline & $\mathrm{E}_{2}=\mathrm{F}_{1}-2003$ & 0,173 & $-0,187$ & 0,134 & $-0,057$ & $-0,064$ \\
\hline & $\mathrm{E}_{3}=\mathrm{F}_{2}-2003$ & 0,149 & $-0,186$ & 0,108 & $-0,029$ & $-0,042$ \\
\hline & Média Conjunta & 0,126 & $-0,172$ & 0,118 & $-0,024$ & $-0,048$ \\
\hline & $\hat{\sigma}_{d(C G C)}^{2}$ & $-4,9^{\text {ns }}$ & $-5,8^{\mathrm{ns}}$ & $-5,4^{\mathrm{ns}}$ & $-5,1^{\mathrm{ns}}$ & $-5,5^{\mathrm{ns}}$ \\
\hline & $\mathrm{R}^{2}$ & 87,72 & 94,14 & 7,70 & 71,05 & 30,76 \\
\hline \multirow[t]{6}{*}{$\mathrm{NG} \mathrm{P}^{-1}$} & $\mathrm{E}_{1}=\mathrm{F}_{1}-2002$ & $-0,107$ & 0,14 & 0,088 & 0,033 & $-0,155$ \\
\hline & $\mathrm{E}_{2}=\mathrm{F}_{1}-2003$ & $-0,113$ & 0,138 & 0,064 & $-0,062$ & $-0,027$ \\
\hline & $E_{3}=F_{2}-2003$ & $-0,072$ & 0,104 & 0,041 & $-0,049$ & $-0,023$ \\
\hline & Média Conjunta & $-0,097$ & 0,128 & 0,064 & $-0,026$ & $-0,068$ \\
\hline & $\hat{\sigma}_{d(C G C)}^{2}$ & $-2,9^{\text {ns }}$ & $-3,17^{\text {ns }}$ & $-3,5^{\mathrm{ns}}$ & $-2,87^{\mathrm{ns}}$ & $-3,07^{\mathrm{ns}}$ \\
\hline & $\mathrm{R}^{2}$ & 34,48 & 52,00 & 94,11 & 86,95 & 95,54 \\
\hline \multirow[t]{6}{*}{$\mathrm{PP}$} & $\mathrm{E}_{1}=\mathrm{F}_{1}-2002$ & $-0,003$ & 0,144 & $-0,029$ & $-0,039$ & $-0,074$ \\
\hline & $\mathrm{E}_{2}=\mathrm{F}_{1}-2003$ & $-0,038$ & 0,163 & $-0,093$ & $-0,051$ & 0,019 \\
\hline & $E_{3}=F_{2}-2003$ & 0,002 & 0,126 & $-0,067$ & $-0,069$ & 0,008 \\
\hline & Média Conjunta & $-0,013$ & 0,145 & $-0,063$ & $-0,053$ & $-0,016$ \\
\hline & $\hat{\sigma}_{d(C G C)}^{2}$ & $-2,9^{\mathrm{ns}}$ & $-3,2^{\mathrm{ns}}$ & $-3,0^{\mathrm{ns}}$ & $-3,8^{\mathrm{ns}}$ & $-3,1^{\mathrm{ns}}$ \\
\hline & $\mathrm{R}_{\mathrm{i}}^{2}$ & 4,00 & 5,00 & 58,70 & 85,70 & 85,70 \\
\hline
\end{tabular}

${ }^{1} \mathrm{PG} \mathrm{P}^{-1}$ (produção de grãos por planta), $\mathrm{NP} \mathrm{P}^{-1}$ (número de panículas por planta), $\mathrm{NG} \mathrm{P}^{-1}$ (número de grãos por panícula) e $\mathrm{PP}$ (peso de panícula).

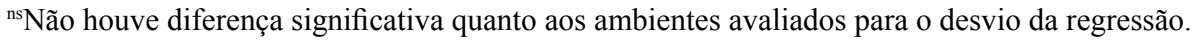




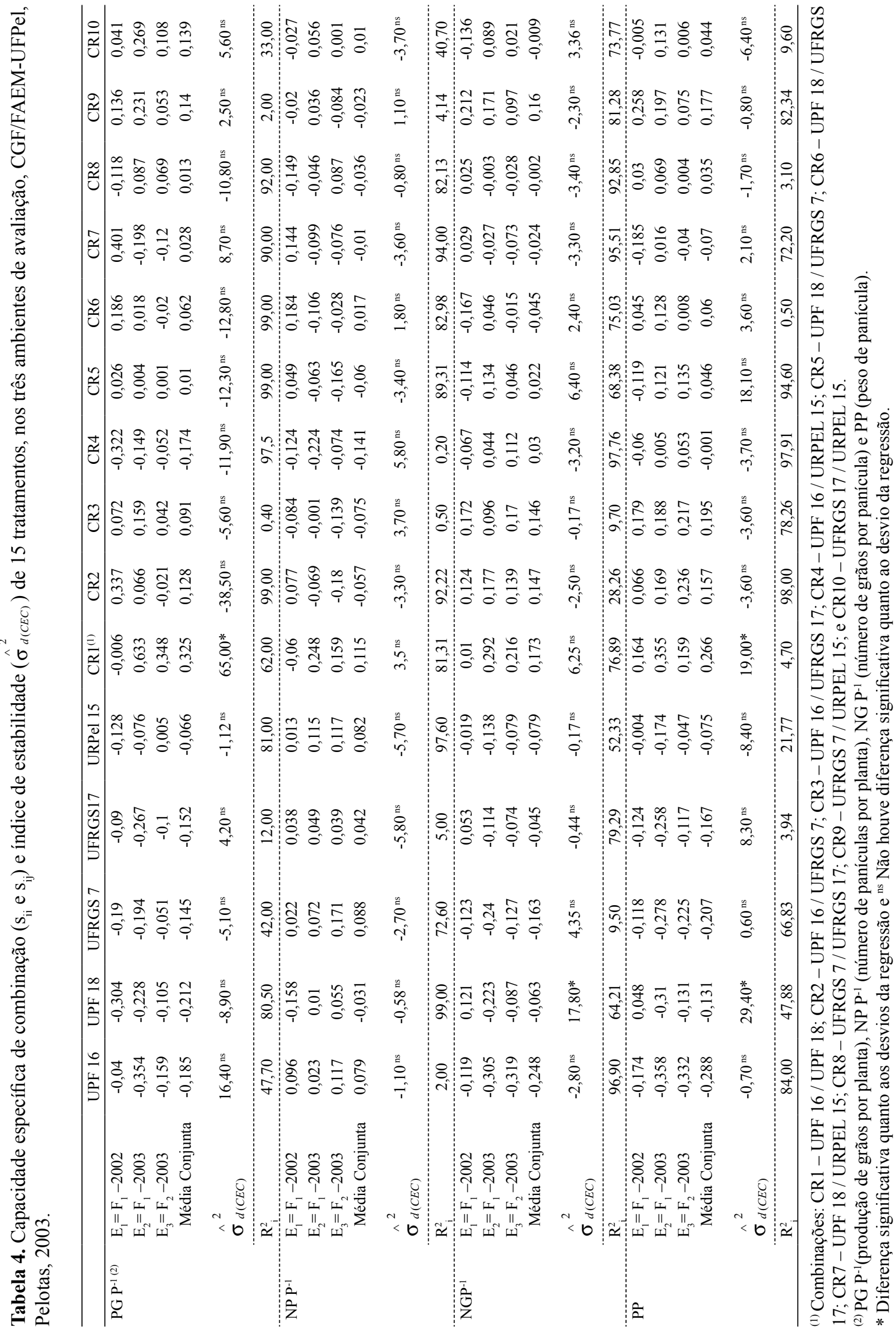


Para o caráter $\mathrm{PG} \mathrm{P}^{-1}$, o maior efeito de CEC foi observado no CR1, quando analisada a média conjunta do efeito, mesmo apresentando valores positivos e negativos na análise individual de cada ambiente. Contudo, seu índice de estabilidade foi estatisticamente diferente de zero, não apresentando, desta forma, boa previsibilidade de comportamento do efeito de CEC, este fato é corroborado pelo desempenho muito inferior no $\mathrm{E}_{1}$ (geração $\mathrm{F}_{1}$ conduzida no ano de 2002) (Tabela 4). Por outro lado, outras combinações específicas merecem destaque, CR3, CR9 e CR10, pois apresentam efeitos positivos de CEC em todos os ambientes de teste, além de evidenciar boa previsibilidade $\left(\hat{\sigma}_{d}^{2}=0\right)$ para o efeito de CEC.

Nenhuma combinação revelou efeitos positivos de CEC para NP $\mathrm{P}^{-1}$ nos três ambientes avaliados individualmente. Apenas três combinações, CR1, CR6 (UPF 18 / UFRGS 17) e CR10, conseguiram evidenciar, na média conjunta dos ambientes, efeitos positivos de CEC, com maior magnitude para CR1, entretanto, com valores positivos e negativos nos distintos ambientes. Por outro lado, todas as combinações evidenciaram boa previsibilidade $\left(\hat{\sigma}_{d}^{2}=0\right)$ para o caráter.

Com base nos resultados de CEC para o caráter NG $\mathrm{P}^{-1}$, a combinação com melhor desempenho foi o
CR1, considerando a média conjunta dos ambientes, além de evidenciar valores positivos em todos os ambientes de teste, não diferindo estatisticamente dos demais em relação ao índice de estabilidade. Com relação ao caráter PP, o CR1 apresentou o maior efeito de CEC, com valores positivos em todos os ambientes, contudo, esta combinação não apresenta bom desempenho de estabilidade para o caráter $\left(\hat{\sigma}_{d}^{2} \neq 0\right)$. Os outros cruzamentos em que foram observados os maiores efeitos de CEC, CR2, CR3 e CR9 para o caráter PP, não diferiram estatisticamente de zero para o índice de estabilidade (Tabela 4).

Conforme Tabela 5, para o parâmetro de desempenho dos caracteres foram verificadas correlações significativas e elevadas somente nas gerações conduzidas no mesmo ano de cultivo $\left(\mathrm{E}_{2} \mathrm{X}\right.$ $\mathrm{E}_{3}$ ), exceto para o caráter $\mathrm{PP}$ e $\mathrm{NP} \mathrm{P}^{-1}$, sendo o último em apenas uma associação. A correlação elevada e significativa dos efeitos de CGC entre todos os ambientes de análise, pode ser verificado para o efeito de CGC exceto para $\mathrm{NG} \mathrm{P}^{-1}$ e PP em duas associações $\left(E_{1} \times E_{2}\right.$ e $\left.E_{1} \times E_{3}\right)$. O mesmo não pode ser verificado no efeito de $\mathrm{CEC}$, sendo correlacionados apenas os efeitos de CEC nos ambientes conduzidos no mesmo ano de teste, exceto para PP, no $E_{1} \times E_{2}$.

Tabela 5. Coeficientes de correlação de Spearman (r) entre os ambientes avaliados $\left(\mathrm{E}_{1}=\mathrm{F}_{1}-2002, \mathrm{E}_{2}=\mathrm{F}_{1}-2003\right.$ e $\mathrm{E}_{3}=\mathrm{F}_{2}-2003$ ) para os parâmetros de desempenho (média das populações e genitores), capacidade geral e capacidade específica de combinação (CGC e CEC) de quatro caracteres de aveia, CGF/FAEM-UFPel, Pelotas, 2003.

\begin{tabular}{|c|c|c|c|c|}
\hline \multirow{2}{*}{ Caracteres $^{(1)}$} & \multirow{2}{*}{ Ambientes $^{(2)}$} & \multicolumn{3}{|c|}{ Parâmetros } \\
\hline & & Desempenho & CGC & CEC \\
\hline \multirow{3}{*}{$\mathrm{PG} \mathrm{P}^{-1}$} & $\mathrm{E}_{1} \mathrm{XE}_{2}$ & 0.39 & $0.60^{*}$ & -0.20 \\
\hline & $\mathrm{E}_{1} \mathrm{XE}_{3}^{2}$ & 0.20 & $0.80^{*}$ & -0.43 \\
\hline & $\mathrm{E}_{2} \mathrm{XE}_{3}$ & $0.90^{*}$ & $0.90^{*}$ & $0.91 *$ \\
\hline \multirow{3}{*}{$\mathrm{NP}^{-1}$} & $\mathrm{E}_{1} \mathrm{XE}_{2}$ & $0.52 *$ & $0.90^{*}$ & -0.32 \\
\hline & $E_{1}^{1} \times E_{3}^{2}$ & 0.35 & $0.90 *$ & -0.38 \\
\hline & $E_{2} X E_{-3}^{3}$ & $0.86^{*}$ & $0.98^{*}$ & $0.30^{*}$ \\
\hline \multirow{3}{*}{$\mathrm{NG} \mathrm{P}^{-1}$} & $\mathrm{E}_{1} \mathrm{XE}_{2}$ & 0.36 & 0.70 & 0.23 \\
\hline & $\mathrm{E}_{1} \mathrm{XE}_{3}^{2}$ & 0.45 & 0.70 & 0.30 \\
\hline & $\mathrm{E}_{2} \mathrm{XE}_{3}^{3}$ & $0.86^{*}$ & $0.98^{*}$ & $0.78^{*}$ \\
\hline \multirow{3}{*}{ PP } & $\mathrm{E}_{1} \mathrm{XE}_{2}$ & $0.73^{*}$ & 0.30 & $0.85^{*}$ \\
\hline & $\mathrm{E}_{1}^{1} \mathrm{XE}_{3}^{2}$ & $0.74 *$ & 0.40 & 0.60 \\
\hline & $\mathrm{E}_{2} \mathrm{XE}_{3}$ & $0.77 *$ & $0.90^{*}$ & $0.63 *$ \\
\hline
\end{tabular}

(1) $\mathrm{PG} \mathrm{P}^{-1}$ (produção de grãos por planta), $\mathrm{NP} \mathrm{P}^{-1}$ (número de panículas por planta), $\mathrm{NG} \mathrm{P}^{-1}$ (número de grãos por panícula) e $\mathrm{PP}$ (peso de panícula). (2) $\mathrm{E}_{1}=\mathrm{F}_{1}-2002 ; \mathrm{E}_{2}=\mathrm{F}_{1}-2003$ e $\mathrm{E}_{3}=\mathrm{F}_{2}-2003$. * Significativo a 5\% de probabilidade pelo teste $t$. 


\section{Discussões}

Os efeitos gênicos determinados pela capacidade geraleespecíficadecombinaçãoorientamomelhorista quanto ao direcionamento efetivo de genitores promissores em cruzamentos (CRUZ; REGAZZI; CARNEIRO, 2004). Contudo, a informação destes parâmetros genéticos aliada aos índices de estabilidade (desvio da regressão) proporcionará maiores detalhes, com vista na escolha das melhores combinações (PACHECO; CRUZ; SANTOS, 1999), ou seja, além da complementaridade de genes, infere-se sobre a probabilidade do efeito genotípico dos complementares se manifestarem em diferentes locais e anos de cultivo (ambientes).

Pode ser destacado neste trabalho, com a significância da interação tratamento vs ambiente, a necessidade de avaliar os efeitos do dialélo (CGC e CEC) de forma conjunta, envolvendo os ambientes distintos, visto que as avaliações em anos isolados não possibilitarão identificar possíveis interações, acarretando em respostas diferenciadas no comportamento das constituições genéticas e, conseqüentemente, menor previsibilidade dos efeitos de um dialelo. Por outro lado, os caracteres PG $\mathrm{P}^{-1}$ e NP $\mathrm{P}^{-1}$ não sofreram influência da geração ou ano de avaliação quanto à $\mathrm{CGC}$, indicando que este efeito oportuniza interpretações conclusivas, com avaliação em um único ambiente. Ou seja, independente do ambiente, os genitores foram efetivos em transmitir à progênie a manifestação fenotípica dos caracteres $\mathrm{PG} \mathrm{P}^{-1} \mathrm{eNPP}^{-1}$, mesmo estes sendo caracteres quantitativos com forte influência do ambiente. Isto sugere que estes caracteres sempre devem ser considerados na escolha de genitores.

$\mathrm{Na}$ CEC, é visível forte alteração em função de ano e geração testada. Com base na geração, esta modificação é esperada em virtude dos efeitos gênicos, pelas interações de dominância e epistasia envolvidas na geração segregante e recombinação de distintos alelos na população. Contudo, as modificações da CEC com base no ano de cultivo evidenciaram de sobremaneira dificuldades em informações mais precisas de comportamento das combinações que oportunizaram incremento de heterose na geração $F_{1}$. Desta forma, é possível confirmar a necessidade de se implementar uma análise dialélica que permita gerar inferências sobre os efeitos da interação associada a um índice de estabilidade.

A forte expressão de heterose no caráter $\mathrm{PG} \mathrm{P}^{-1}$, evidenciado nas gerações conduzidas no mesmo ano de avaliação ( $E_{2}$ e $\left.E_{3}\right)$, destaca a redução de vigor de $F_{1}$ a $F_{2}$, sendo fundamental para $o$ melhorista, visto que combinações que evidenciem o maior valor heterótico na geração $F_{1}$ oportunizam, conseqüentemente, incremento no número de classes genotípicas de seleção na geração $\mathrm{F}_{2}$.

A superioridade dos valores de QM (\%) da CGC sobre a CEC indica que os efeitos gênicos aditivos foram de maior importância na maioria dos caracteres, podendo resultar em maior consistência da expressão destes caracteres na geração $F_{2}$ (ALLARD, 1999). Estes resultados estão de acordo com os obtidos para a cultura do trigo onde os efeitos aditivos também foram predominantes (JOSHI et al., 2004). Com relação à análise de médias, os genitores com desempenho significativamente superior foram aqueles que apresentaram na média dos ambientes avaliados os maiores efeitos de CGC, ou seja, UPF 16 para $\mathrm{PG} \mathrm{P}^{-1}$ e NP $^{-1}$ e UPF 18 para NG $\mathrm{P}^{-1}$ e PP, sugerindo que um maior progresso genético pode ser obtido para estes caracteres.

Mesmo com o efeito da interação significativo

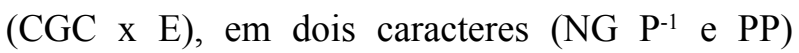
não foi encontrada diferença significativa entre os genótipos para a estabilidade dos efeitos de CGC, provavelmente em virtude das avaliações serem realizadas em apenas três ambientes, sendo dois destes, gerações conduzidas no mesmo ano. Desta forma, inferências em um maior número de ambientes e anos de avaliação poderão ser mais decisivas na discrepância entre os efeitos de CGC para os genótipos avaliados. Além disso, a análise realizada com maior número de genitores poderá 
incrementar no uso desta metodologia, por outro lado, poderia ocasionar maiores dificuldades com o maior número de combinações a realizar.

O elevado desempenho de CGC dos genótipos UPF 16 e UFRGS 7 para $\mathrm{PG}^{-1}$ e NP $\mathrm{P}^{-1}$ revela um elevado potencial genético desses genitores em transferir alelos favoráveis visando melhorar o desempenho das populações, pois quanto mais elevados forem os efeitos de $\mathrm{g}_{\mathrm{i}}$ (CGC), positivos ou negativos, esse genitor poderá ser considerado muito superior ou inferior aos demais incluídos no dialelo (CRUZ; REGAZZI; CARNEIRO, 2004). Dessa forma, a utilização destes em blocos de cruzamento, com o objetivo de incrementar a produtividade de grãos e o número de panículas em aveia, hipótese embasada na complementaridade de genes, sugere que ao serem combinados com os demais, determinem maior amplitude efetiva de seleção, com grande probabilidade na obtenção de progênies superiores (CARVALHO et al., 2001). O mesmo pode ser evidenciado para o genótipo UPF 18 , no que se refere aos caracteres $\mathrm{NG} \mathrm{P}^{-1}$ e PP. A prioridade depositada em genótipos com elevada CGC, se deve ao fato de os mesmos oportunizarem maior efetividade e facilidade de seleção pela ação de genes aditivos envolvidos na expressão do caráter, sendo, importante para espécies autógamas por serem fixados ao longo das sucessivas gerações de autofecundação (CRUZ; REGAZZI; CARNEIRO, 2004).

Foi observado para o genótipo UPF 18 o pior desempenho de CGC para o caráter NP $\mathrm{P}^{-1}$. Com efeito reduzido e negativo e média de classe inferior, possibilita inferir que o uso deste genótipo em blocos de cruzamento poderá implicar na redução do $\mathrm{NP} \mathrm{P}^{-1}$. Este fato é indesejável para cultura da aveia, uma vez que estudos recentes demonstram que o caráter NP $\mathrm{P}^{-1}$ está correlacionado com $\mathrm{PG}$ $\mathrm{P}^{-1}$, sendo, portanto, de considerável importância na escolha de constituições genéticas que maximizem a produção em aveia (LORENCETTI et al., 2006). Por outro lado, para o caráter PP, deve ser enfatizado o uso deste genótipo (UPF 18) em programas de melhoramento, seja na recomendação de genótipos elite ou na indicação de cruzamentos com o objetivo de seleção indireta através do $\mathrm{PG}$ $\mathrm{P}^{-1}$ em virtude do elevado valor de CGC para PP. Diversos estudos demonstram o grande potencial do caráter PP como critério de seleção indireta para PG $\mathrm{P}^{-1}$ (BENIN et al., 2003; CAIERÃO et al., 2001; KUREK et al., 2002) Além disso, resultados obtidos por e Chandhanamutta e Frey (1973) e Chapko e Brinkman (1991) e demonstram que o peso de panícula apresentou elevadas correlações fenotípicas com o número de grãos/panícula, variando de 0,57 a 0,90 , confirmando a efetividade do PP na seleção indireta para rendimento de grãos. Possivelmente, o sucesso da utilização do PP deve-se principalmente a dois fatores: elevada herdabilidade do caráter $\mathrm{e}$ forte associação com rendimento de grãos $\left(\mathrm{PG} \mathrm{P}^{-1}\right)$ (MARCHIORO et al., 2003).

Conforme destacam Cruz, Regazzi e Carneiro (2004), na avaliação das melhores combinações híbridas, devem ser consideradas não apenas as estimativas de CGC $\left(\mathrm{g}_{\mathrm{i}}\right)$ e de CEC $\left(\mathrm{s}_{\mathrm{ij}}\right)$, mas também as estimativas de CEC no comportamento per se $\left(\mathrm{s}_{\mathrm{ii}}\right)$, permitindo a melhor escolha dos híbridos. Nesse sentido, através da estimativa de $\mathrm{s}_{\mathrm{ii}}$ nas diferentes gerações e anos de cultivo, ficou constatada a herança unidirecional para todos os caracteres avaliados. Conforme destacam Cruz, Regazzi e Carneiro (2004), o modelo bidirecional somente pode ser encontrado quando há predominância de valores positivos e negativos do parâmetro $\mathrm{s}_{\mathrm{ii}}$.

O sinal do parâmetros ii $_{\text {ii }}$ dica a direção dos desvios de dominância do caráter. Desta forma, quando $\mathrm{o}$ valor de $\mathrm{s}_{\mathrm{ii}}$ for negativo, o genitor i contribuirá positivamente para a heterose, e quanto maior for o valor absoluto de $\mathrm{s}_{\mathrm{ii}}$, maior será sua contribuição para a heterose de seus híbridos (CRUZ; REGAZZI; CARNEIRO, 2004; CRUZ; VENCOVSKY, 1989). Nesse sentido, os genótipos UPF 16 e UPF 18 são os que proporcionam a maior heterose positiva nos híbridos para $\mathrm{PG}^{-1}$, considerando o comportamento médio dos genitores nos distintos ambientes, em virtude de apresentar valores de magnitude mais 
elevada, de sinal negativo. Além disto, não foi verificado quanto ao índice de estabilidade $\left(\hat{\sigma}_{d}^{2}\right)$ diferença significativa entre os genótipos testados para o caráter. Para o caráter NP $\mathrm{P}^{-1}$, os genótipos UPF 16, UFRGS 7 e URPel 15 são os que possuem os maiores valores com vistas à heterose negativa nos híbridos, resultante do comportamento médio inferior de um híbrido em relação à média de seus genitores. Porém, a heterose negativa, observada no uso destes genótipos, deve ser justificada pela dominância direcionada à redução da expressão do caráter. Em relação aos caracteres $\mathrm{NG} \mathrm{P}^{-1}$ e PP, pode ser verificado para o índice de estabilidade do efeito CEC $\left(\mathrm{s}_{\mathrm{ii}}\right)$, a reduzida previsibilidade do genótipo UPF 18, frente aos ambientes testados, indicando grande dificuldade de interpretações dos parâmetros genéticos relacionados ao uso deste genótipo em diferentes combinações.

Os efeitos da capacidade específica de combinação $\left(\mathrm{s}_{\mathrm{ij}}\right)$ ou CEC correspondem ao desvio do desempenho médio de uma combinação particular em relação à média dos genitores envolvidos no cruzamento (FALCONER, 1981). Neste sentido, o uso do CR1, é de grande valia para o melhorista com valores positivos e elevados CEC para todos os caracteres avaliados, considerando a média conjunta dos ambientes, pois, conforme verificado neste trabalho, ao menos um genótipo em cada combinação híbrida realizada com estes genitores, possui elevado efeito de CGC, já que UPF 16 possui os maiores efeitos de CGC para $\mathrm{PG}^{-1}$ e NP $\mathrm{P}^{-1}$, enquanto que UPF 18 revela os maiores efeitos para $\mathrm{NG} \mathrm{P}^{-1} \mathrm{e} \mathrm{PP}$, fato este que deve ser levado em consideração, pela maior contribuição de genes de efeito aditivo para o caráter.

Para Cruz, Regazzi e Carneiro (2004), a combinação híbrida mais favorável deve ser aquela que, além de apresentar maior estimativa da CEC, seja resultante de um cruzamento em que pelo menos um dos genitores apresente elevada CGC. Contudo, esta combinação evidenciou diferença quanto à análise de médias e na previsibilidade dos efeitos de CEC em relação às outras combinações avaliadas para os caracteres em estudo. Neste sentido, esta falta de consistência dos resultados de estabilidade do efeito de CEC para o CR1, nos diferentes caracteres avaliados, revela que os mecanismos genéticos que governam a heterose em aveia são largamente influenciados pelas variações do ambiente. Desta forma, possíveis inferências de parâmetros genéticos devem ser obtidos em diferentes ambientes, preferivelmente em diferentes gerações e anos de cultivo. Somente assim, pode ser possível avançar com cruzamentos promissores e ter sucesso em um programa de melhoramento para caracteres de controle genético complexo.

Desta maneira, pode ainda ser destacado para CEC do caráter $\mathrm{PG} \mathrm{P}^{-1}$, os CR2, CR9 e CR10, de boa previsibilidade $\left(\hat{\sigma}_{d}^{2}=0\right)$, conforme destacam Cruz, Regazzi e Carneiro (2004), índice de estabilidade zero ou próximo a zero evidenciam previsibilidade na expressão fenotípica do caráter. Além disso, evidenciam média estatisticamente igual ao CR1. Para o caráter PP, o CR3 revela ser o de maior destaque, não só pelo bom desempenho de estabilidade do efeito $\left(\hat{\sigma}_{d}^{2}=0\right)$, mas também por apresentar efeito heterótico positivo, resultado do desempenho superior a médias dos genitores. Para os caracteres $\mathrm{NG} \mathrm{P}^{-1}$ e NP $\mathrm{P}^{-1}$, o cruzamento de maior efeito de CEC (CR1), revelando valores com boa previsibilidade de CEC nos diferentes ambientes avaliados e desempenho estatisticamente superior na média conjunta, sendo, portanto preferível na indicação de constituições genéticas com base em mais de um parâmetro de avaliação.

Pode ser ainda dado ênfase à combinação UPF 16 / UFRGS 7 (CR2), como destaque para NGP, com um elevado efeito de CEC, e desempenho médio conjunto estatisticamente igual ao CR1 (UPF 16 / UPF 18), além de boa previsibilidade do efeito CEC $\left(\hat{\sigma}_{d}^{2}=0\right)$. Convém ainda ressaltar o efeito heterótico positivo desta combinação, onde o resultado médio deste cruzamento supera significativamente o comportamento médio dos genitores envolvidos no cruzamento, manifestando a grande participação de locos dominantes que elevaram o valor do caráter. 
Desta forma, de acordo com os resultados obtidos por Benin et al. (2005b) e Lorencetti et al. (2006), os quais estabelecem a real associação de caracteres pelas correlações positivas e elevadas de NGP, PP, NP $\mathrm{P}^{-1}$ com $\mathrm{PG} \mathrm{P}^{-1}$, podem ser indicadas possíveis combinações para o incremento no $\mathrm{PG} \mathrm{P}^{-1}$, via seleção indireta nestes caracteres, como observado nos cruzamentos CR1, CR3 e CR2, para NP $\mathrm{P}^{-1}$, PP e $\mathrm{NG} \mathrm{P}^{-1}$, respectivamente.

A significância da grande maioria dos valores de correlação entre os efeitos de CGC nos diferentes ambientes revela o grande potencial destes genótipos para uso em programas de melhoramento com o objetivo de inferir sobre o efeito de CGC, com grande previsibilidade de desempenho, ou seja, diminuindo a necessidade de avaliar em vários ambiente.

A avaliação das populações em diferentes gerações e anos de cultivo foi determinante na identificação das melhores constituições genéticas com base na previsibilidade do efeito de CEC, o que demonstra a necessidade de considerar mais de uma geração e/ou ano de avaliação na indicação de diferentes constituições genéticas com base nos efeitos dialélicos de CEC. Desta forma, podem ser obtidos respostas mais conclusivas e eficientes, de modo a obter efetivo ganho genético em diferentes processos de condução de populações de aveia.

\section{Conclusões}

Os genótipos avaliados revelam grande potencial de se inferir sobre o efeito de CGC, com grande previsibilidade de desempenho. Para a discriminação das melhores constituições genéticas pelo efeito da CEC, o uso de avaliações em diferentes gerações e anos de cultivo é determinante.

Os cruzamentos entre UPF 16 x UPF 18, UPF 16 x UFRGS 7 e UPF 16 x UFRGS 17, se revelam promissores no incremento do rendimento de grãos via seleção indireta através do número de panículas por planta, número de grãos por panícula e peso de panícula, respectivamente.

\section{Agradecimentos}

Os autores agradecem a CAPES, CNPq e FAPERGS pelo suporte financeiro para este trabalho.

\section{Referências}

ALLARD, R. W. Principles of plant breeding. New York: John Wiley, 1999.

BARBOSA NETO, J. F.; MATIELLO, R. R.; CARVALHO, F. I. F.; OLIVEIRA, J. M. S.; PEGORARO, D. G.; SHNEIDER, F.; SORDI, M. E. B.; VACARO, E. Progresso genético no melhoramento da aveia-branca no Sul do Brasil. Pesquisa Agropecuária Brasileira, Brasília, v. 35, n. 8, p. 1605-1612, 2000.

BENIN, G.; CARVALHO, F. I. F.; OLIVEIRA, A. C. C.; MARCHIORO, V. S.; LORENCETTI, C.; KUREK, A. J.; SILVA, J. A. G.; CARGININ; A.; SIMIONI, D. Estimativas de correlações e coeficientes de trilha como critérios de seleção para rendimento de grãos em aveia. Revista Brasileira de Agrociência, Pelotas, v. 9, n. 1, p. 9-16, 2003.

BENIN, G.; CARVALHO, F. I. F.; OLIVEIRA, A. C.; LORENCETTI, C.; VIEIRA, E. A.; COIMBRA, J. L. M.; VALÉRIO, I. P.; FLOSS, E. L.; BERTAN, I.; SILVA, G. O. Adaptabilidade e estabilidade em aveia em ambientes estratificados. Ciência Rural, Santa Maria, v. 35, n. 2, p. 295-302, 2005a.

BENIN, G.; CARVALHO, F. I. F.; OLIVEIRA, A. C.; HARTWIG, I.; SCHMIDT, D.; VIEIRA, E. A.; VALÉRIO, I. P.; SILVA, J. A. G. Estimativas de correlações genotípicas e de ambiente em gerações com elevada freqüência de heterozigotos. Ciência Rural, Santa Maria, v. 35, n. 3, p. 523-529, 2005 b.

CAIEIRÃO, E.; CARVALHO, F. I. F.; PACHECO, M. T.; LORENCETTI, C.; MARCHIORO, V.; SILVA, J. A. G. Seleção indireta em aveia para o incremento no rendimento de grãos. Ciência Rural, Santa Maria, v. 31, n. 2, p. 231-236, 2001.

CARVALHO, F. I. F.; FEDERIZZI, L. C.; NODARI, R. O.; FLOSS, E.; GANDIN, C. L. Analysis of stability parameters and of genotype $\mathrm{x}$ environment interaction in oats grain yield in Rio Grande do Sul (Brasil). Revista Brasileira de Genética, Ribeirão Preto, v. 5, n. 3, p. 517 532, 1982.

CARVALHO, F. I. F.; SILVA, S. A.; KUREK, A. J.; MARCHIORI, V. S. Estimativas e implicações da herdabilidade como estratégia de seleção. Pelotas: Ed. da UFPel, 2001. 
CHANDHANAMUTTA, P.; FREY, K. J. Indirect mass selection for grain yield in oat populations. Crop Science, Madison, v. 13, n. 4, p. 470-473, 1973.

CHAPKO, L. B.; BRINKMAN, M. A. Interrelationships between panicle weight, grain yield and grain yield components in oat. Crop Science, Madison, v. 31, n. 4, p. 878-882, 1991.

CRUZ, C. D.; REGAZZI, A. J.; CARNEIRO, P. C. S. Modelos biométricos aplicados ao melhoramento genético. Viçosa: Ed. da UFV, 2004.

CRUZ, C. D.; VENCOVSKY, R. Comparação de alguns métodos de análise dialélica. Revista Brasileira de Genética, Ribeirão Preto, v. 12, n. 2, p. 425-438, 1989.

CRUZ, C. D. Programa Genes: aplicativo computacional em genética e estatística. Viçosa: Ed. da UFV, 2001.

EBERHART, S. A.; RUSSEL, W. A. Stability parameters for comparing varieties. Crop Science, Madison, v. 6, n. 1, p. 36-40, 1966.

FALCONER, D. S. Introdução à genética quantitativa. Viçosa: Ed. da UFV, 1981.

FEDERIZZI, L. C.; BARBOSA NETO, J. F.; CARVALHO, F. I. F.; VIAU, L. V. M.; SEVERO, J. L.; FLOSS, E. L.; ALVES, A.; ALMEIDA, J.; SILVA, A. C. Estabilidade do rendimento de grãos em aveia: efeito do uso de fungicidas. Pesquisa Agropecuária Brasileira, Brasília, v. 28, n. 4, p. 465-472, 1993.

GERALDI, I. O.; MIRANDA FILHO, J. B. Adapted models for the analysis of combining ability of varieties in partial diallel. Revista Brasileira de Genética, Ribeirão Preto, v. 11, n. 2, p. 419-430, 1988.

GRIFFING, B. Concept of general and specific combining ability in relation to diallel crossing systems. Australian Journal of Biological Sciences, Collingwood, v. 9, n. 4, p. 463-493, 1956.
JOSHI, S. K.; SHARMA, S. N.; SINGHANIA, D. L.; SAIN, R. S. Combining ability in the F1 and F2 generations of diallel cross in hexaploid wheat (triticum aestivum L. em. Thell). Heredity, New York, v. 141, n. 2, p. 115-121, 2004.

KUREK, A. J.; CARVALHO, F. I. F.; OLIVEIRA, A. C.; CARGNIN, A.; MARCHIORO, V. S.; LORENCETTI, C. Coeficiente de correlação entre caracteres agronômicos e de qualidade de grãos e sua utilidade na seleção de plantas de aveia. Ciência Rural, Santa Maria, v. 32, n. 3, p. 371-376, 2002.

LEFFEL, R. C.; WEISS, M. G. Analysis of diallel crosses among ten varieties of soybeans. Agronomy Journal, Madison, v. 50, n. 9, p. 528-534, 1958.

LORENCETTI, C.; CARVALHO, F. I. F.; MARCHIORO, V. S.; BENIN, G.; OLIVEIRA, A. C.; FLOSS, E. L. Implicações da aplicação de fungicida nos parâmetros de adaptabilidade e estabilidade de rendimento de grãos em aveia branca . Ciência Rural, Santa Maria, v. 34, n. 4, p. 693-700, 2004.

LORENCETTI, C.; CARVALHO, F. I. F.; OLIVEIRA, A. C.; VALÉRIO, I. P.; HARTWIG, I.; BENIN, G.; SCHMIDT, D. Aplicability of phenotypic and canonic correlations and path coefficients in the selection os oat genotypes. Scientia Agrícola, Piracicaba, v. 63, n. 1, p. 11-19, 2006.

MARCHIORO, V. S.; CARVALHO, F. I. F. OLIVEIRA, A. C.; LORENCETTI, C.; BENIN, G.; SILVA, J. A. G.; KUREK, A.; HARTWIG, I. Herdabilidade e correlações para caracteres de panícula em populações segregantes de aveia. Revista Brasileira de Agrociência, Pelotas, v. 9, n. 4, p. 323-328, 2003.

PACHECO, C. A. P.; CRUZ, C. D.; SANTOS, M. X. Association between Griffing's diallel and the adaptability and stability analyses of Eberhart and Russell. Genetics and Molecular Biology, São Paulo, v. 22, n. 3, p. 451456, 1999.

SAS LEARNING EDITION. Getting started with the SAS Learning Edition. Care: SAS Institute Inc., 2002. 
